Research Article

\title{
True-Triaxial Drained Test of Tengger Desert Sand
}

\author{
Xuefeng Li $\mathbb{D}^{1,2}$ Zhigang $\mathrm{Ma}^{2}{ }^{2}$ Wennan $\mathrm{Lu}^{2}$, and Yandong Wang ${ }^{2}$ \\ ${ }^{1}$ Solid Mechanics Institute, Ningxia University, Yinchuan 750021, China \\ ${ }^{2}$ School of Physics and Electronic-Electrical Engineering, Ningxia University, Yinchuan 750021, China
}

Correspondence should be addressed to Xuefeng Li; lixuefeng1928@163.com

Received 16 May 2020; Revised 12 August 2020; Accepted 27 August 2020; Published 9 September 2020

Academic Editor: Xuzhen He

Copyright (c) 2020 Xuefeng Li et al. This is an open access article distributed under the Creative Commons Attribution License, which permits unrestricted use, distribution, and reproduction in any medium, provided the original work is properly cited.

For the lack of accurate test results in design and maintenance of desert-crossing highways in the Tengger Desert of western China, the GDS true-triaxial system was used to conduct the drained test on dense sand. Under the condition of different intermediate principal stress ratio $b$-value, the results showed that the stress-strain relationships in three orthogonal directions had significant differences, presenting significant anisotropy. The peak of the generalized shear stress increased with the increase of $b$-value. Except under the condition of $b=0$, the specimen contracted firstly and then dilated, while the others dilated. The results of the different confining pressures showed that the stress-strain relationships appeared as a hardening type at low confining pressures, and as the confining pressure increased, the stress-strain relationships exhibit hardening, peaking, softening, and stable deformation characteristics. At low confining pressure, the contractive behaviors were not obvious, mainly as dilatancy, and as the confining pressure increased, the dilatancy increased gradually. The specimen transformed contract to dilatancy, and when the confining pressure reached $800 \mathrm{kPa}$, the specimen exhibited contractive behavior. The test results will provide data for subgrade design and construction in desert area.

\section{Introduction}

The particular mechanical properties of aeolian sand in Tengger Desert have brought about great challenges to the construction and maintenance of desert-crossing highways in northwest China. The Tengger Desert, located in northwestern China, is one of the four deserts and is also a typical enrichment area of aeolian sand with an area of $42,700 \mathrm{~km}^{2}$ [1]. Aeolian sand in Tengger Desert is a special road-building or subgrade material, which has the basic characteristics of low water content, large plasticity, low particle surface activity, and strong permeability. The aeolian sand has uniformed sand particles (the particle size is mainly distributed between $0.075 \mathrm{~mm}$ and $0.5 \mathrm{~mm}$, which belongs to fine sand) and belonged to poor gradation, which has engineering characteristics such as low bearing capacity of foundation and two specific properties, that is, compaction, "bimodal characteristic," and collapsibility. The "bimodal characteristic" is that there are two peaks in the compacting curve of aeolian sand at zero water content and at the optimum content rate. Yuan and Wang [2], Li et al. [3], and
Yin and Wang [4] studied the compaction of aeolian sand and found that the aeolian sand achieved high compactness under the condition of drying and saturation. In general, these studies provide a theoretical basis for the compaction process of subgrade in the desert area. Aeolian fine sand is a kind of collapsible soil that is affected by many factors such as fines content and dry density, and the more fines content, the stronger the collapsibility $[5,6]$. The additional settlement that occurred after the wetting of the sand proposed by Wang et al. [7] also proved the collapsibility characteristics of the sand indirectly. These particular properties of aeolian sand bring about great difficulties to desert highway, desert railway, electric power facilities, and engineering construction and maintenance $[8,9]$.

Due to development needs, the engineering construction scale in the Tengger Desert has expanded year by year, and the mechanical characteristics of aeolian sand need to be analyzed, but the studies on it with the triaxial test are scarce; only Deng et al. [10], Song [11], and Liu et al. [12] have carried out the static and dynamic test with the conventional triaxial apparatus, while the results of the true-triaxial test 
are still blank. To understand the 3D mechanical properties, the research results of other types of sand are introduced briefly at first. An earlier design by Kjellman [13], a six-piece rigid plate-controlled true-triaxial apparatus, has attracted wide attention by studying the strength of sand. Later, many drained tests have obtained the changes that the sand strength increased first and then decreased with the increase of $b$-value; for example, Bishop [14] tested for sand, Ko and Scott [15] tested for Ottawa sand, Sutherland and Mesdary [16] tested for Lock Aline sand, Lade and Duncan [17] tested for Monterey sand, and Li [18] tested for Chengde medium dense sand. The true-triaxial drained tests of Fujian standard sand conducted by Zhang et al. [19] showed that the larger $b$ value is, the more obvious the dilatancy of sand is. In addition, confining pressure has a great influence on the $3 \mathrm{D}$ strength of sand [20]. The results of the true-triaxial test conducted by Schofield and Wroth [21] showed that loose sand exhibited contractive behavior and no shear stress peak under low confining pressure, while dense sand exhibited dilatancy and shear stress peak. Xu and Ying [22] conducted true-triaxial drained tests on silt, fine sand, and medium dense sand and revealed the evolutions of stress strain with three particle sizes under different confining pressures and the evolutions of lateral deformation when the $b$-value was equal to zero. Hu et al. [23] conducted true-triaxial drained tests on Shanghai fine sand, where the tests' results showed that the shear stress peak increased with the increase of the initial confining pressure, but the relationships between shear stress and the $b$-value are complex. Zhang et al. [24] and Huang et al. [25] analyzed the stress-strain relationships and the evolutions of pore pressure and major principal strain of Fujian standard sand under different confining pressures. To predict the deformation degree of medium dense sand in engineering accurately, Li et al. [26] analyzed the influencing factors and characteristics of the deformation and strength under different confining pressures. Shariatmadari et al. [27] conducted true-triaxial drained and undrained tests on sand-PET (Polyethylene Terephthalate) mixtures under different confining pressure, which showed that the shear stress peak under high confining pressure is higher than that under low confining pressure obviously, and the contractive behaviors and dilatancy of the mixed sand are almost the same under the drained and undrained conditions. Krabbenhoft et al. [28] conducted triaxial tests on dry sand under different confining pressures and pointed out that friction is related to stress state.

In the desert region, the successive constructions of highway, railway, and power transmission network projects have accumulated a lot of experience for highway design, construction, and maintenance in the northwest of China, such as the longest desert highway in China (Tarim Desert Highway) [29]. However, most of the existing studies on desert sand are still focused on the determination of basic mechanical properties such as sedimentary structure of dune, grain-size characteristics, settlement and compaction characteristics, and so forth, and few systematic studies focused on its deformation, sheer strength, and failure characteristics from the perspective of engineering requirements [30-32]. Therefore, a series of drained tests on the Tengger Desert sand were conducted in this paper using the true-triaxial apparatus of British GDS company, which systematically studied the stress-strain relationships and the volumetric strain of dense specimens in different $b$-value and the different confining pressures with the same $b$-value. The aim is to explore the strength and deformation characteristics of the Tengger Desert sand in 3D space and provide a reference and guidance for desert-crossing highways, railway, and engineering construction and later maintenance.

\section{Brief Introduction and Improvement of True-Triaxial Apparatus}

2.1. Equipment Introduction. The British GDS true-triaxial apparatus is mainly composed of host, pressure chamber, pressure controller, and GDSLab data acquisition system; see Figure 1. The host uses high-speed servo motor to control major principal stress $\sigma_{1}$ and intermediate principal stress $\sigma_{2}$ independently, with the maximum static load of $20 \mathrm{kN}$ and the maximum dynamic load of $10 \mathrm{~Hz}$, which can realize the rapid loading of a variety of dynamic and static stress paths. The direction of minor principal stress $\sigma_{3}$ is controlled flexibly, and the air pressure loading is controlled by the pneumatic controller. GDSLab is an automatic setting and test data acquisition system.

2.2. Improvement of Loading Plate. There are two problems in using rigid loading plate for true-triaxial apparatus. First, when the size of the plates is close to that of the specimen, a small deformation will cause the rigid plates to collide with each other, and the test will be completed. Second, when the sample is too large compared to the size of the loading plate, the specimen produces boundary effect, which affects the test precision. Based on the above questions, many experts have done a lot of work in this research field [16].

The true-triaxial apparatus of GDS adopts the loading mode combining rigid plate and flexible plane. The loading device is shown in Figure 2. The rigid plates control the directions of $\sigma_{1}$ and $\sigma_{2}$. When the specimen deformation is large, the loading plates will collide with each other. Although limit protection is set in GDSLab, the device stops after a small displacement in the direction of $\sigma_{2}$ because the side dimensions of the specimen are close to the size of the plate. In order to ensure that the test can be carried out smoothly without producing boundary effect, an organic plastic plate of equal size is pasted on both sides of the loading plate of the true-triaxial apparatus to increase the limit of the loading plate. The plastic plate is made of material with large elastic modulus, so the deformation caused by it can be ignored.

\section{Test Process}

3.1. Basic Characteristics of Tengger Desert Sand. The aeolian sand for the test was collected from the central area of Tengger Desert in Shapotou, Ningxia, China. The maximum dry density is $1.62 \mathrm{~g} / \mathrm{cm}^{3}$. The minimum dry density is $1.36 \mathrm{~g} / \mathrm{cm}^{3}$. 


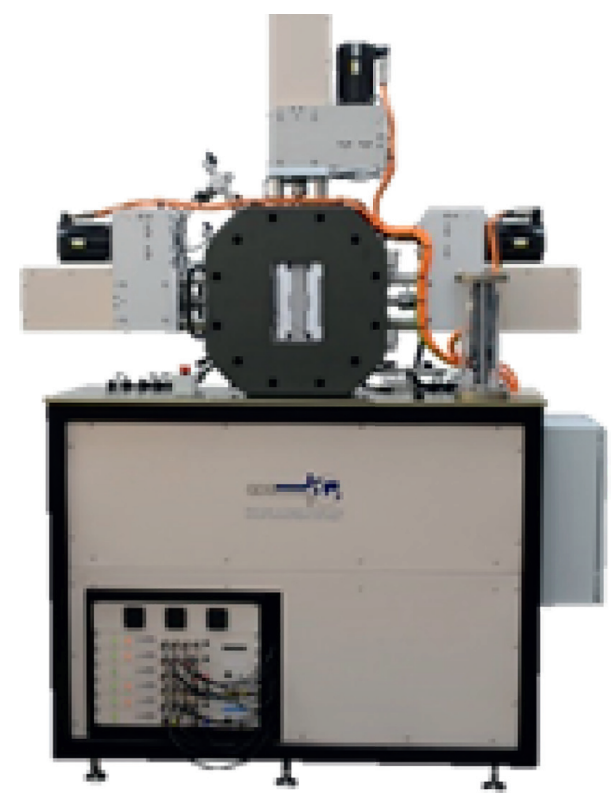

FIgURE 1: British GDS true-triaxial apparatus.

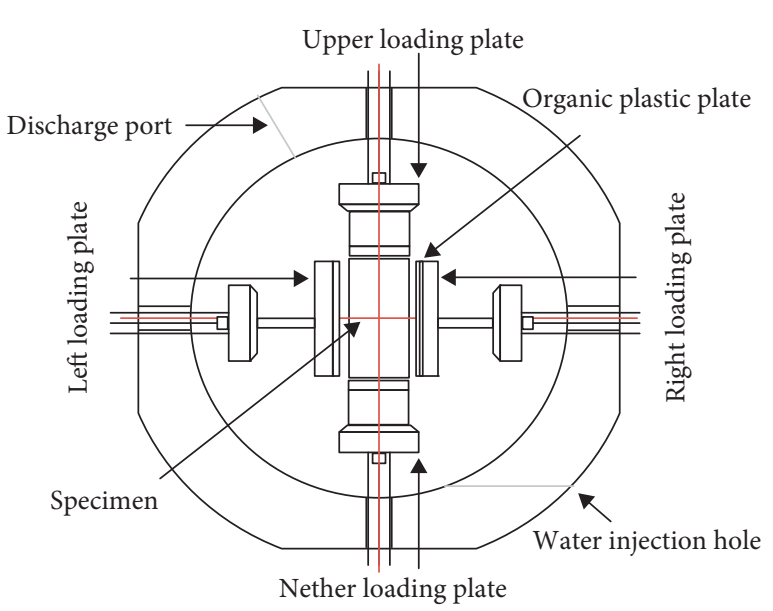

Figure 2: Diagram of true-triaxial pressure chamber.

The natural density is $1.52 \mathrm{~g} / \mathrm{cm}^{3}$. The water content is $0.14 \%$. The void ratio is 0.7 . Figure 3 shows the particle size distribution curves of Tengger Desert sand measured by the laser particle size analyzer. It is clear from the particle analysis experiment that the Tengger Desert sand belongs to fine sand. Other particle grading parameters and basic physical properties of the samples are shown in Table 1.

The dense-sand specimens with relative compactness $D_{r}$ of 0.7 are prepared. According to the size of specimen, the volume of the specimen is calculated to be $843750 \mathrm{~mm}^{3}$, and the total weight of sand required for specimen preparation is $1291 \mathrm{~g}$. The expression of relative compactness $D_{r}$ is

$$
D_{r}=\frac{e_{\max }-e_{0}}{e_{\max }-e_{\min }}=\frac{\left(\rho_{d}-\rho_{d \min }\right) \rho_{d \max }}{\left(\rho_{d \max }-\rho_{d \min }\right) \rho_{d}},
$$

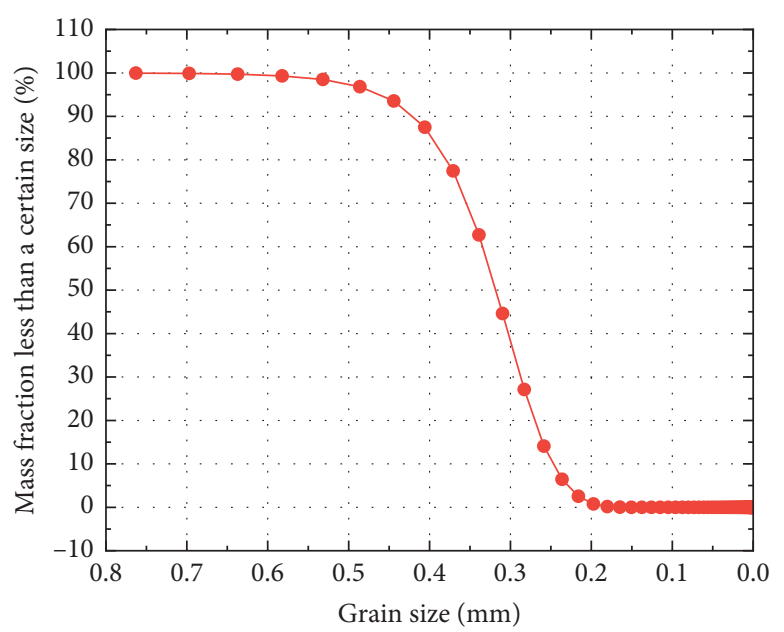

Figure 3: Particle size distribution curves of Tengger Desert sand.

where $e_{\max }$ is the void ratio of sand in the loosest state. $e_{0}$ is the void ratio of sand in the natural state. $e_{\min }$ is the void ratio of sand in the densest state. $\rho_{d \min }$ is the dry density of sand in the loosest state. $\rho_{d \max }$ is the dry density of sand in the densest state. $\rho_{d}$ is the dry density of sand in the natural state.

3.2. Specimen Preparation and Installation. The length, width, and height of the specimen are $75 \mathrm{~mm}, 75 \mathrm{~mm}$, and $150 \mathrm{~mm}$, respectively. To ensure the test stability, the height error of the specimen is controlled to be no more than $3 \mathrm{~mm}$ generally, that is, less than $2 \%$. The brief steps of specimen preparation and installation are as follows:

(1) Finally, made the base and rubber film completely contact to achieve the sealing effect.

(2) The vacuum pump was used to suck the air between the rubber film and the specimen preparation member to make the rubber film and the specimen preparation member fit fully.

(3) Using the method of layering dry deposition (Figure 4 ), the specimen was prepared by dividing the weighing $1291 \mathrm{~g}$ of sand into 10 parts. The specimen was evenly distributed into the specimen preparation member with a funnel.

(4) The height of the prepared dense-sand specimen was checked, whether the specimen was flat was tested, and the filter paper was put after meeting the requirements.

(5) Vaseline was rubbed on the four faces of the upper base of the upper actuator and it was placed on the top of the specimen; and the rubber film and rubber ring were installed.

(6) The vacuum pump was disconnected, all valves connected with the specimen were closed, and the corresponding pipelines were connected. The backpressure pipeline was connected to the vacuum pump. The vacuum pump was opened to generate negative pressure in the sand specimen (Figure 5). 
TABle 1: Physical property indices of Tengger Desert sand.

\begin{tabular}{lccccc}
\hline Name & Average particle diameter, $D_{50}(\mathrm{~mm})$ & $\begin{array}{c}\text { Median particle } \\
\text { size, } D_{30}(\mathrm{~mm})\end{array}$ & $\begin{array}{c}\text { Effective } \\
\text { particle size, } D_{10}(\mathrm{~mm})\end{array}$ & $\begin{array}{c}\text { Nonuniform } \\
\text { coefficient, } C_{u}\end{array}$ & $\begin{array}{c}\text { Curvature } \\
\text { coefficient, } C_{c}\end{array}$ \\
\hline Tengger Desert sand & 0.33 & 0.30 & 0.26 & 1.42 \\
\hline
\end{tabular}
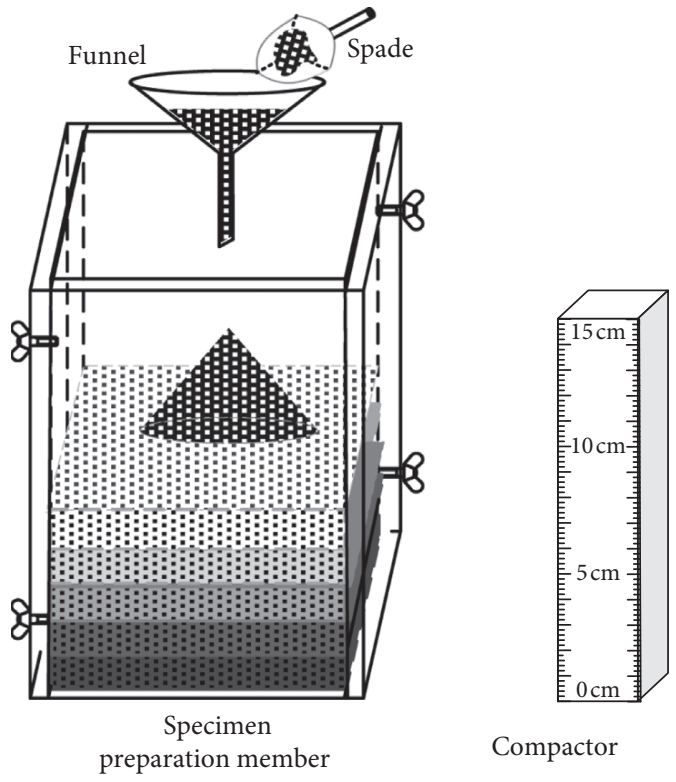

Compactor

FIGURE 4: Specimen preparation by layering dry deposition.

The process of specimen preparation and installation is shown in Figure 5.

3.3. Saturation and Consolidation. Due to its dry characteristics, aeolian sand often takes a long time to fully saturate. Hydraulic saturation was used for specimen firstly, and then back pressure was applied to saturation. The saturation degree of the specimen is determined by the pore water pressure coefficient $B$. When $B \geq 0.95$, the specimen is considered to reach the saturation state. $B$, the discrimination method proposed by Skempton [33], was the pore water pressure increment caused by unit confining pressure increment when the specimen was subjected to hydrostatic pressure; that is, $B=\Delta u / \Delta \sigma_{3}$. If $B \geq 0.95$ was met in all the tests, saturation ended.

After the saturation test, the isotropic consolidation was conducted for the specimens. When the volume of water discharged from the sand specimen was less than $1 \%$ within 30 minutes, the consolidation was considered to be completed. In this paper, the confining pressure was effective when it was consolidated, and the consolidation time was about 1.5 2 hours.

3.4. Loading Scheme. The test adopted strain control. To study the laws of strength, the stress-strain and dilatancy relationships, and so forth in Tengger Desert sand under different $b$ and different confining pressures, ten kinds of test schemes were set up, which are shown in Tables 2 and 3.
Table 2 shows four loading schemes with effective confining pressure of $100 \mathrm{kPa}$ and $b$ of $0,0.25,0.5$, and 0.75 (we set separately when $b$ is equal to 1 ). Under these four loading conditions, two rigid loading plates and a flexible loading plane were adopted for control.

In order to better overcome the loading plate collision and boundary effect in the loading process of true-triaxial apparatus, the strain control loading method was adopted in the test. The $b$-value was also controlled by the proportion of strain distribution in three directions. Hence, according to the definition of $b$-value, the expression of intermediate principal strain ratio $b_{\varepsilon}$ is

$$
b_{\varepsilon}=\frac{\varepsilon_{2}-\varepsilon_{3}}{\varepsilon_{1}-\varepsilon_{3}}, \quad\left(0 \leq b_{\varepsilon} \leq 1\right),
$$

where $\varepsilon_{1}, \varepsilon_{2}$, and $\varepsilon_{3}$ are the strains in the directions of $\sigma_{1}, \sigma_{2}$, and $\sigma_{3}$, respectively.

By using the two governing formulas of equation (2) and volumetric strain equation $\varepsilon_{v}=\varepsilon_{1}+\varepsilon_{2}+\varepsilon_{3}$, the true-triaxial apparatus could be controlled to realize the test control scheme of different $b$-value or different $b$-value with constant volume. Nevertheless, as a matter of fact, since the truetriaxial apparatus of GDS restricts the directions of $\sigma_{1}$ and $\sigma_{2}$ to be vertical and horizontal rigid loading plates, respectively, when $b=1$, the loading scheme was the same as the conventional triaxial elongation test scheme. In this case, the direction of $\sigma_{1}$ was horizontal and the test scheme needed to be set separately. In the case of Table 3, the test scheme of five kinds of confining pressure under the condition of $b=0$ was given, and the aim was to get the critical state line of the Tengger Desert sand under the conventional triaxial compression condition. In combination with the test scheme in Table 2, shear tests were conducted under the loading path condition of constant $\sigma_{3}$ of $100 \mathrm{kPa}$ at an effective confining pressure of $100 \mathrm{kPa}$ to obtain the deformation and strength curves of Tengger Desert sand in 3D space. The strain control path of the test is shown in Figure 6.

\section{Test Results}

4.1. Triaxial Test Analysis of Tengger Desert Sand with Different $b$-Value. Figure 7 shows the actual changes of $b$ in the whole loading process of different loading schemes designed in Tables 2 and 3. It is concluded from the figure that although the strain control mode is adopted in the test to complete the shear process by controlling $b_{\varepsilon}$, the actual $b$-value in Figure 6 is also stable at the target value required by the test except for $b=0.25$, so the strain control mode can fully meet the requirements of the test design. The reason why the actual $b$-value exceeded the value of its definition when the strain control $b=0.25$ was used for loading may be the large boundary effect or the uneven density control. 


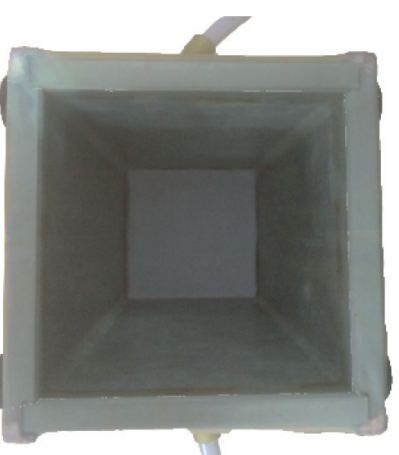

(a)

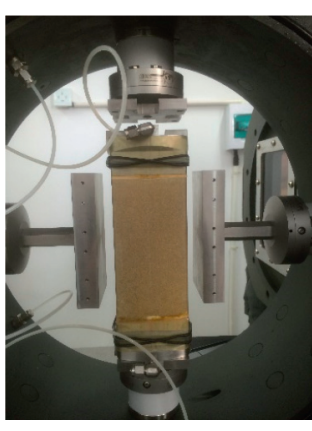

(b)

FiguRE 5: Sample preparation and installation. (a) Specimen preparation member. (b) Installation.

TABLE 2: Loading schemes with different $b$.

\begin{tabular}{lccc}
\hline$b$ & $\begin{array}{c}\text { Time } \\
(\mathrm{min})\end{array}$ & $\begin{array}{c}\text { Effective confining } \\
\text { pressure }(\mathrm{kPa})\end{array}$ & Loading scheme \\
\hline 0 & & & $\begin{array}{l}\text { Two rigid loading plates and a flexible loading plane were used in the test. After isotropic } \\
\text { consolidation, according to the definition of } b_{\varepsilon} \text { in equation }(2) \text { and controlled by } b_{\varepsilon}=d \varepsilon_{2} / d \varepsilon_{1},\end{array}$ \\
0.25 & 240 & 100 & $\begin{array}{c}\varepsilon_{1} \text { and } \varepsilon_{2} \text { were set, and the confining pressure was kept constant; that is, the load of equal } b \text { was } \\
0.5\end{array}$ \\
0.75 & & & realized
\end{tabular}

TABLE 3: Loading schemes with different $\sigma_{3}$ at $b=0$.

\begin{tabular}{ccc}
\hline $\begin{array}{l}\text { Time } \\
(\mathrm{min})\end{array}$ & $\begin{array}{c}\text { Effective confining } \\
\text { pressure }(\mathrm{kPa})\end{array}$ & Loading scheme \\
\hline & 50 & The rigid loading plate and two flexible loading plane controls were used in the test. The horizontal \\
& 100 & loading plate was kept separate from the specimen, pressure was applied in the axial direction with \\
strain control loading, $\varepsilon_{1}$ was set as $25 \%$, axial strain velocity was set as $0.21 \% /$ min, and the strain in \\
the two horizontal flexible loading directions was the same
\end{tabular}

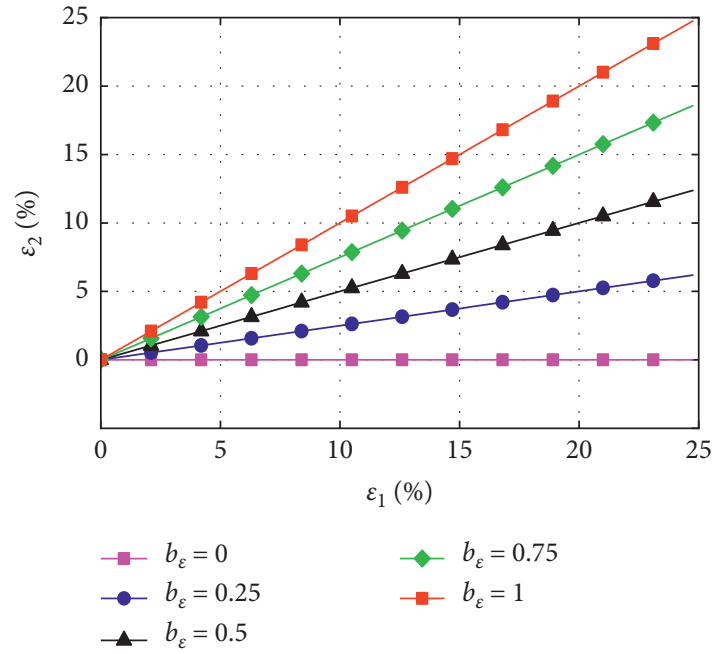

FIgURE 6: Strain path control.

Figure 8 shows the stress-strain relationships under different $b$-value at the same confining pressure in $3 \mathrm{D}$ space; the stress is generalized shear stress $q$ and the strain is

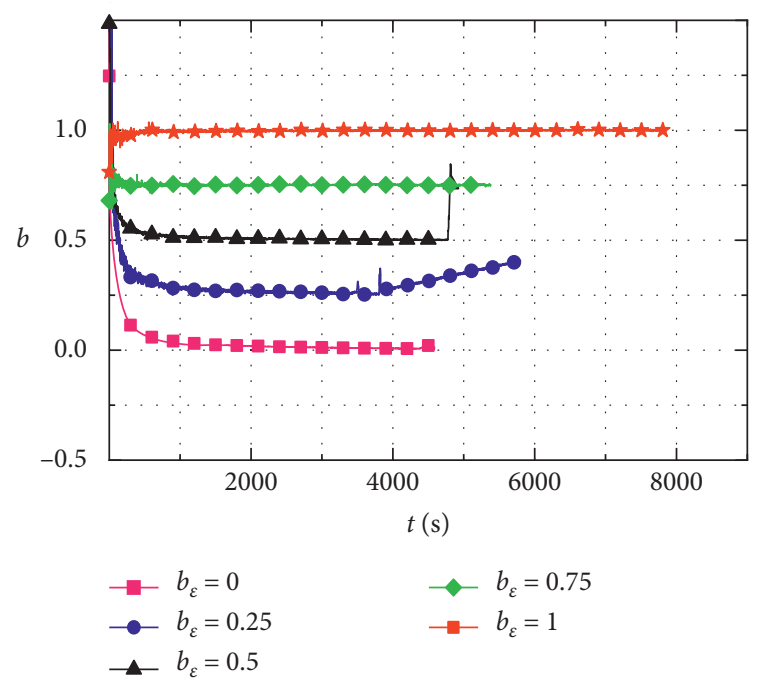

Figure 7: Stress path diagram at $\sigma_{3}$ of $100 \mathrm{kPa}$.

principal strain $\varepsilon$ in the three principal directions. The strain control method is adopted in the test of all schemes. During the shear process, $b$-value is relatively constant, and, at the 

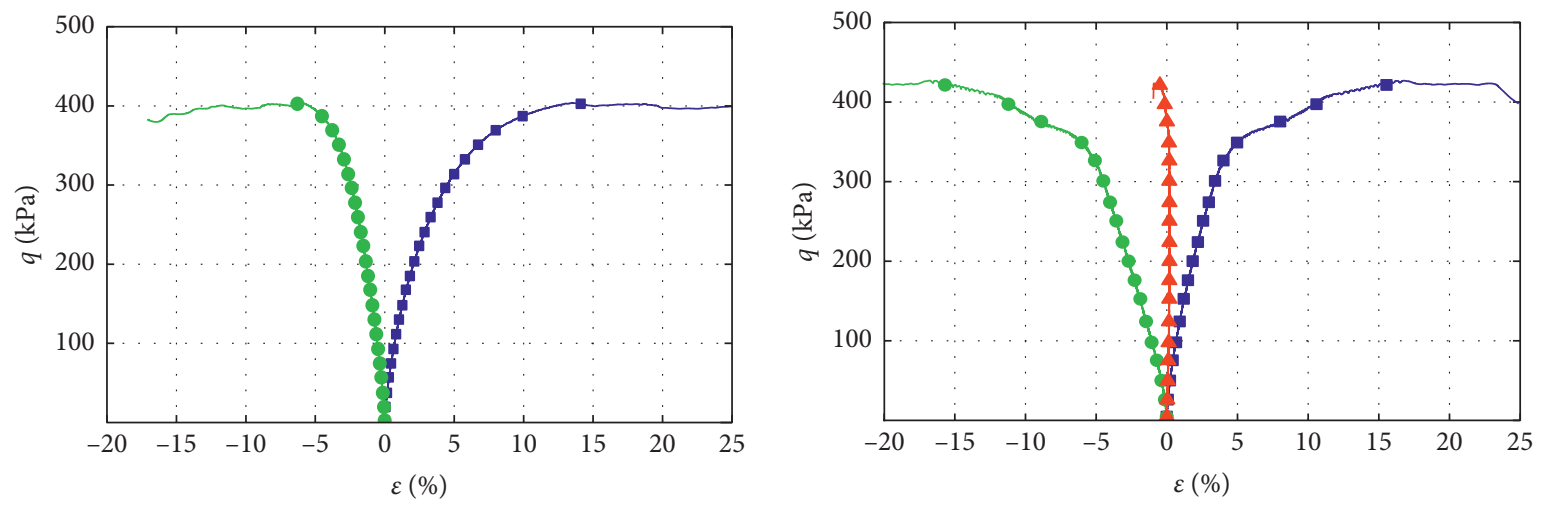

$100 \mathrm{kPa}$

$\rightarrow \varepsilon_{1}$

$100 \mathrm{kPa}$

$\rightarrow \varepsilon_{1}$

$\neg \varepsilon_{2}$

$\multimap \varepsilon_{3}$

(a)
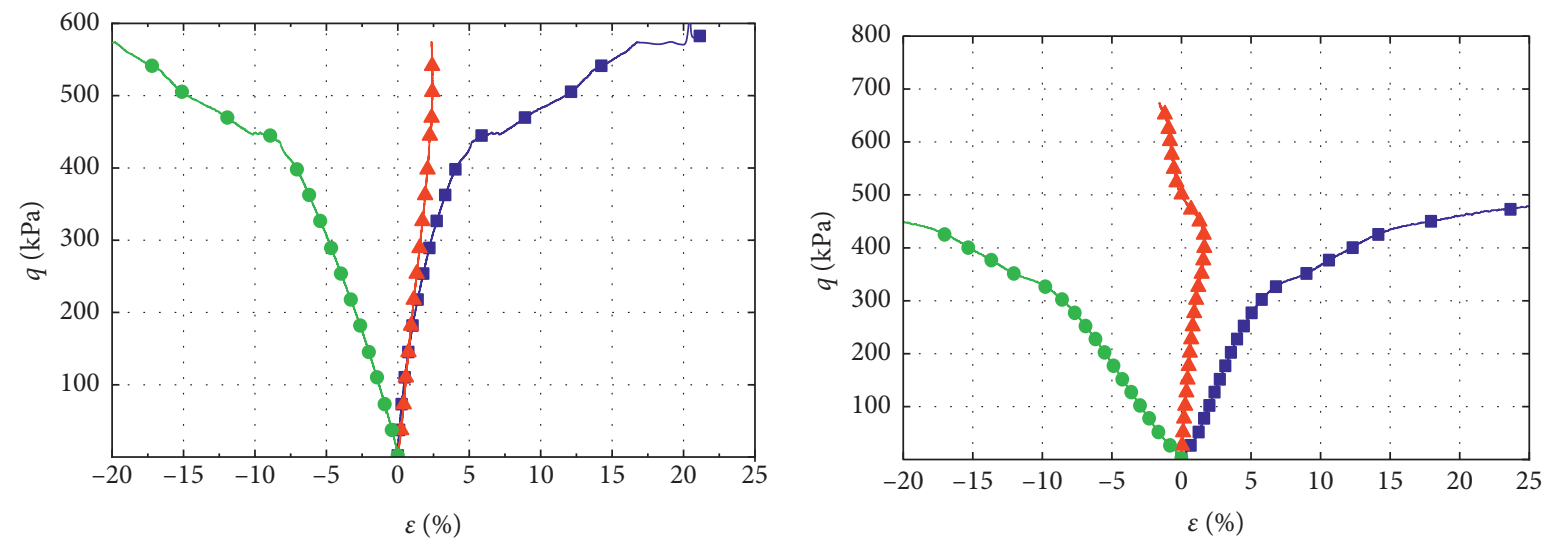

$100 \mathrm{kPa}$

$\rightarrow-\varepsilon_{1}$

$100 \mathrm{kPa}$

$\simeq \varepsilon_{2}$

$\rightarrow-\varepsilon_{1}$

$\neg \varepsilon_{2}$

$\longrightarrow \varepsilon_{3}$

(c)

(d)

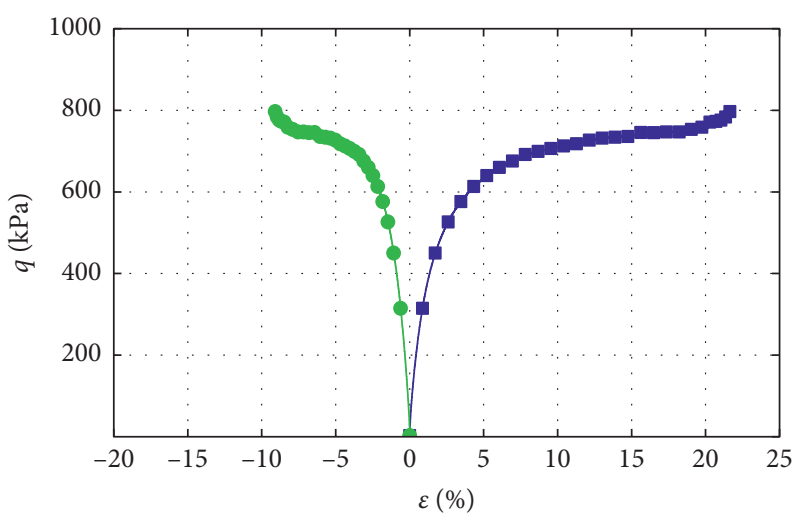

$100 \mathrm{kPa}$

$\rightarrow-\varepsilon_{1}$

(e)

FIGURE 8: Stress-strain relationships of different $b$. (a) $b=0$. (b) $b=0.25$. (c) $b=0.5$. (d) $b=0.75$. (e) $b=1$. 


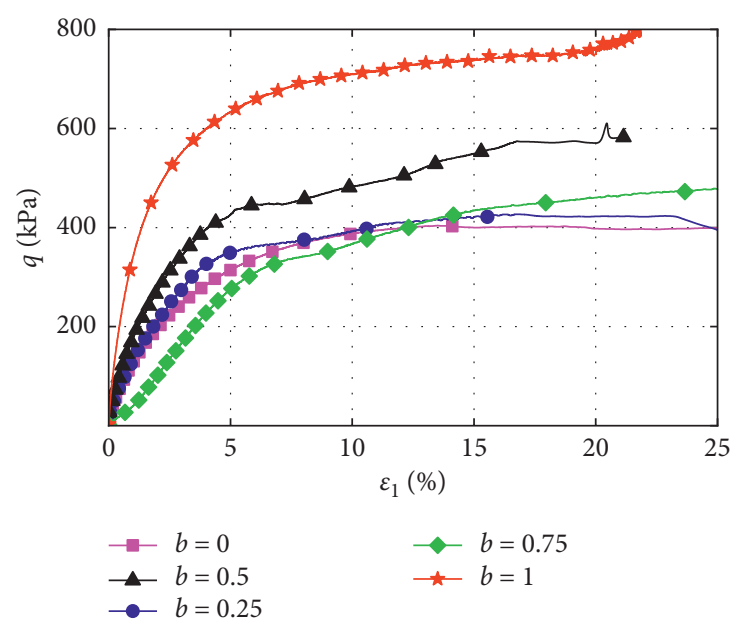

Figure 9: The relationships of $q-\varepsilon_{1}$ at $\sigma_{3}$ of $100 \mathrm{kPa}$.

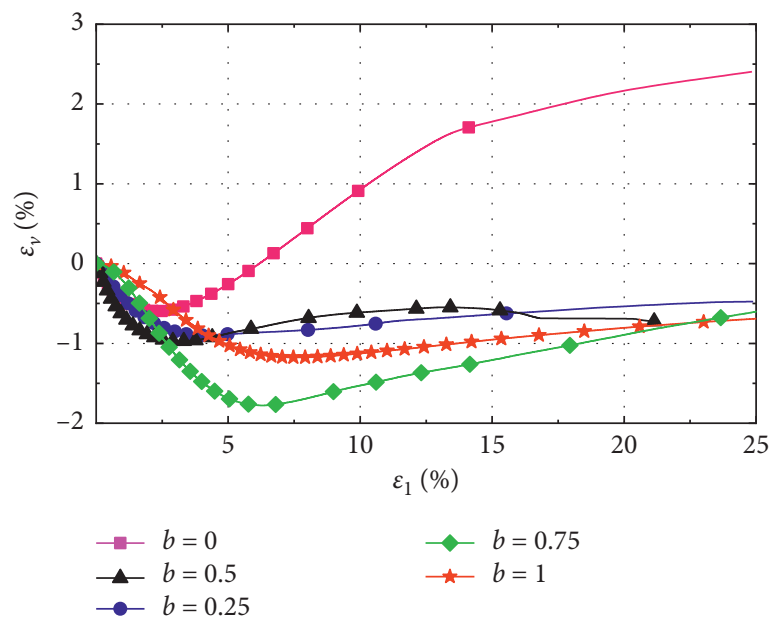

Figure 10: The relationships of $\varepsilon_{v}-\varepsilon_{1}$ at $\sigma_{3}$ of $100 \mathrm{kPa}$.

same time, the constant value of $\sigma_{3}$ is $100 \mathrm{kPa}$ in the whole shear process, which is equal to the confining pressure. The aims of the test are to obtain the relationships of $q-\varepsilon$ in $3 \mathrm{D}$ space. It is concluded from Figure 8 that the relationships of $q-\varepsilon$ are obviously different with the changes of the $b$-value, which are influenced obviously by it.

Figure 9 shows the relationships of $q-\varepsilon_{1}$ under different $b$-value at confining pressure of $100 \mathrm{kPa}$. It is obtained intuitively from Figure 9 that, on the whole, all test $q$ increases with the increase of $b$, showing hardening type, and then increases slowly with the increase of $b$ and tends to be stable finally. Except for $b=0.75$, the peak of $q$ increases with the increase of $b$. At last, the peak of $q$ reaches the maximum value when $b=1$. Among all $b$, the peak of $q$ is the smallest when $b=0$ and the biggest when $b=1$.

Figure 10 shows the relationships of $\varepsilon_{v}-\varepsilon_{1}$ under the different conditions of $b$ at confining pressure of $100 \mathrm{kPa}$. It is inferred from Figure 10 that, except for $b=0$, the test results of Tengger Desert sand show contractive behavior first and then dilatancy under the same confining pressure.
Under other values of $b$, the specimen is contractive and then reaches the minimum value of volumetric strain and then has small dilatancy on the basis of the minimum value, but, on the whole, the sand shows contractive behavior. The difference is that the degrees of contractive behavior and dilatancy are different. Among the specimens with contractive behavior, the contractive behavior and small dilatancy are the most obvious under the condition of conventional compression test $(b=0)$.

4.2. Triaxial Test Analysis of Tengger Desert Sand under Different Confining Pressure. Figure 11 shows the relationships of $q-\varepsilon$ under different confining pressures. Under the same condition of $b$, the $3 \mathrm{D}$ relationships of $q-\varepsilon$ show hardening type under low confining pressure and then tend to be stable. With the increase of confining pressure, the specimens show hardening first and then reach the peak, followed by softening, and then they tend to be stable finally. On the whole, the strength of sand increased significantly with the increase 

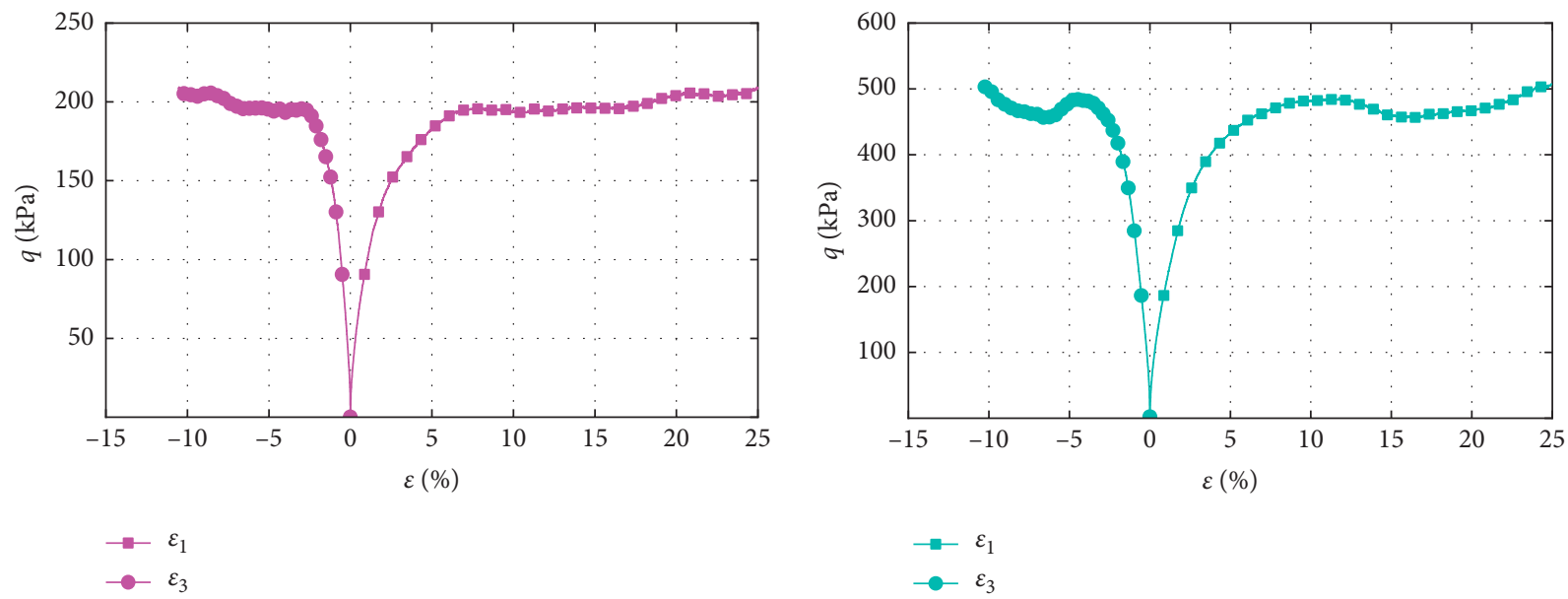

(a)
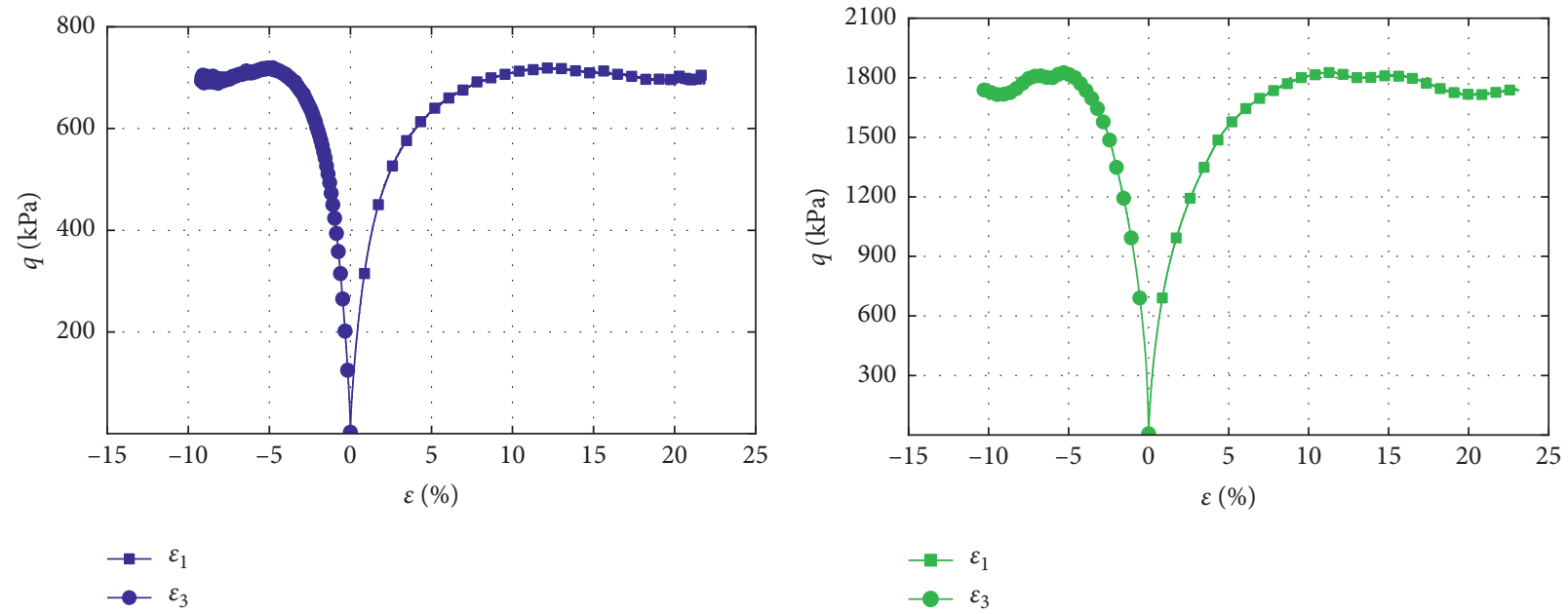

(c)

(d)

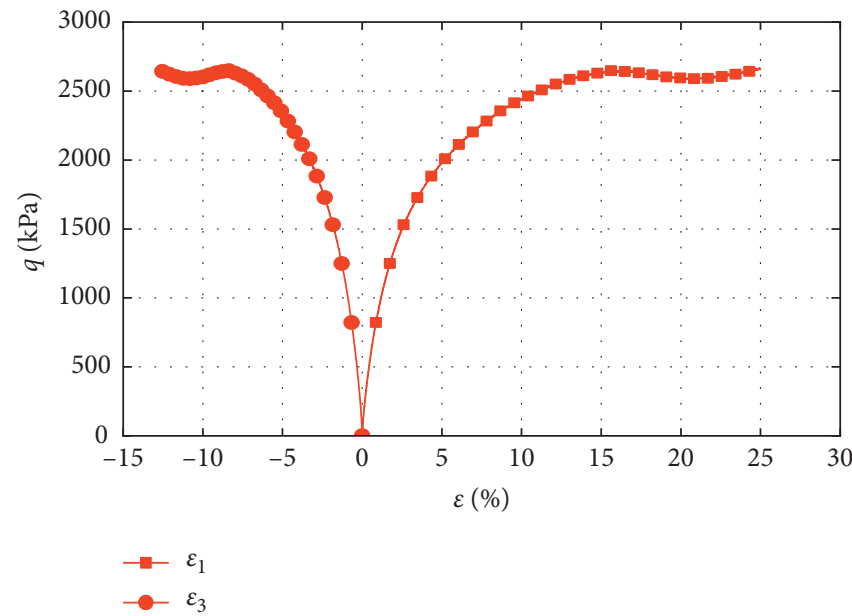

(e)

Figure 11: The relationships of $q$ and $\varepsilon$ at different $\sigma_{3}$. (a) $\sigma_{3}=50 \mathrm{kPa}$. (b) $\sigma_{3}=100 \mathrm{kPa}$. (c) $\sigma_{3}=200 \mathrm{kPa}$. (d) $\sigma_{3}=400 \mathrm{kPa}$. (e) $\sigma_{3}=800 \mathrm{kPa}$. 


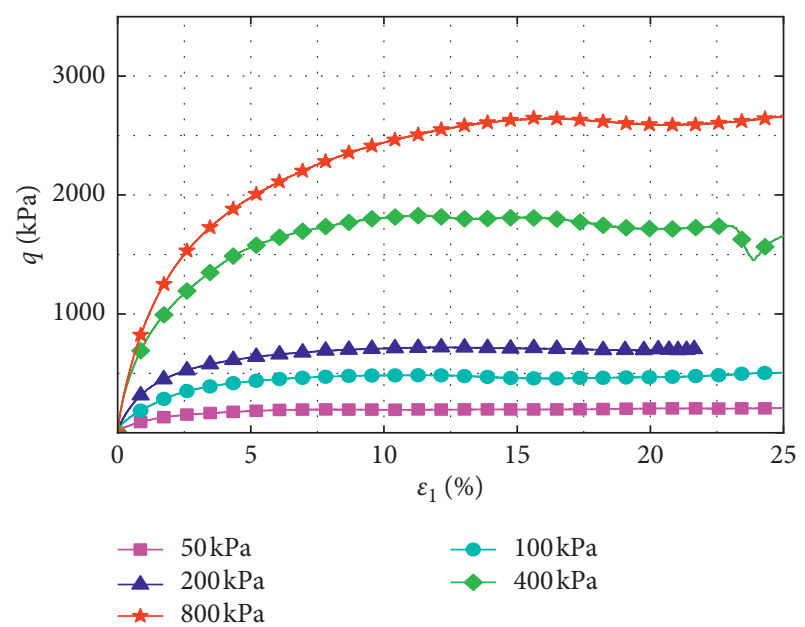

Figure 12: The relationships of $q$ and $\varepsilon_{1}$ under different $\sigma_{3}$.

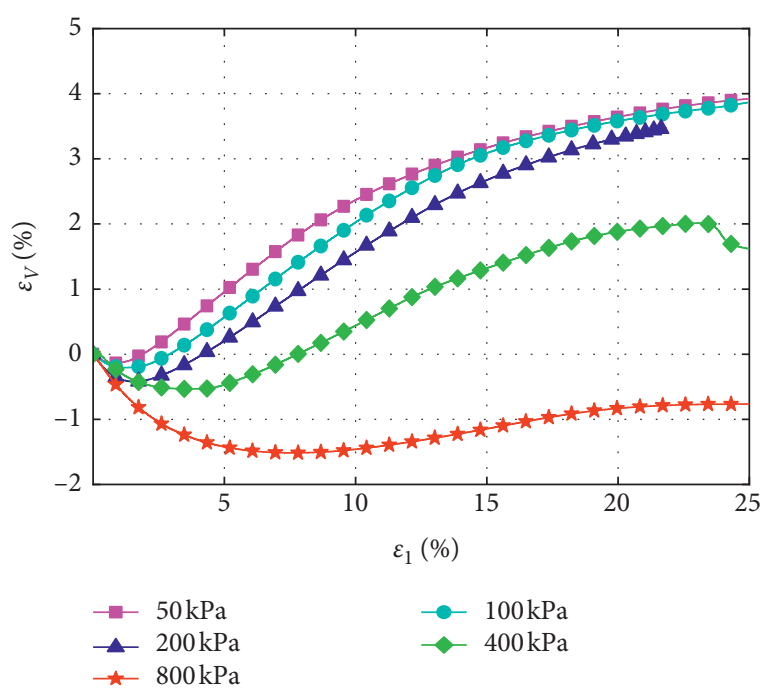

Figure 13: The relationships of $\varepsilon_{v}$ and $\varepsilon_{1}$ at different $\sigma_{3}$.

of confining pressure, and the variation lows of $\varepsilon_{1}$ and $\varepsilon_{3}$ are different significantly too.

Figure 12 shows the relationships of $q-\varepsilon_{1}$ under different confining pressures with $b=0$. With the increase of confining pressure, the strength of Tengger Desert sand with the same compactness increases monotonously under the same stress path.

Figure 13 shows the $\varepsilon_{v}-\varepsilon_{1}$ relationships of Tengger Desert sand specimens under different confining pressures. It is presented from Figure 13 that the contractive behavior of the sand specimen in Tengger Desert is not obvious under the condition of low confining pressure, which is mainly manifested as dilatancy. With the increase of confining pressure, the contractive behavior begins to increase, and the dilatancy weakens. The whole specimen transforms from dilatancy to contractive behavior. When the confining pressure reaches $800 \mathrm{kPa}$, the specimen shows contractive behavior completely.

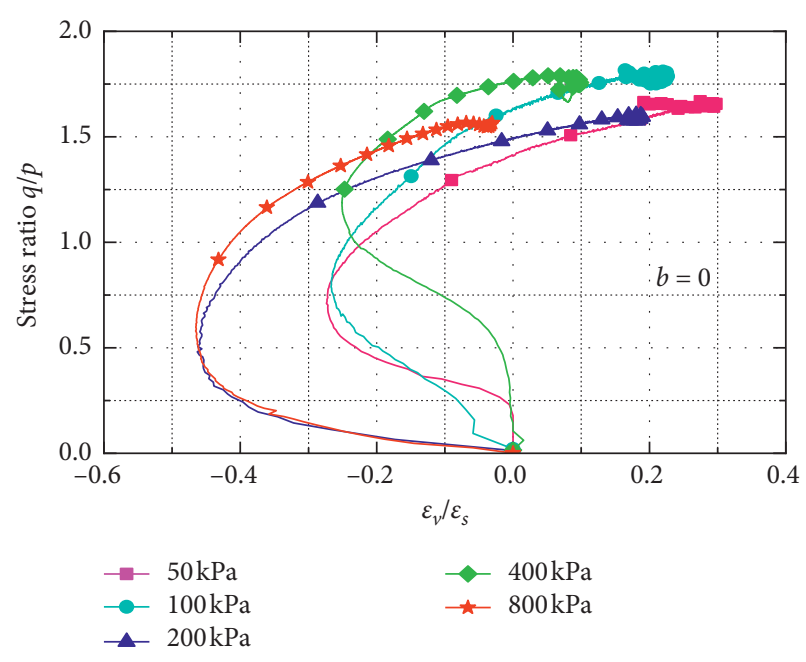

FIGURE 14: The relationships of $q / p$ and $\varepsilon_{v} / \varepsilon_{s}$.

In Figure 13, under the condition of confining pressure of $50 \mathrm{kPa}$, the specimens show contractive behavior at $\varepsilon_{1}<2 \%$. After $\varepsilon_{1}>2 \%$, dilatancy increases rapidly, and the maximum volumetric strain reaches $4 \%$. At a confining pressure of $400 \mathrm{kPa}$, the whole characteristic is contractive behavior at $\varepsilon_{1}<8 \%$, while the dilatancy is observed at $\varepsilon_{1}>8 \%$ and the maximum volumetric strain is $2 \%$. When the confining pressure is $800 \mathrm{kPa}$, the specimen shows contractive behavior completely even if a slight dilatancy appears after the minimum volumetric strain in contractive behavior. Figure 14 shows the relationships between stress ratio and volumetric strain in Figure 13 under several confining pressures, which provides reference for the establishment of dilatancy relationships in 3D space of Tengger Desert sand.

\section{Conclusion}

To study the strength and deformation characteristics of desert sand when the highways are paved under saturated construction conditions in this paper, the true-triaxial test was used to determine the above characteristics of Tengger Desert sand under the 3D condition, which provided basic test support for the desert-crossing highway design, railway, construction, and maintenance in the northwest of China. The main conclusions were as follows.

The specimens of Tengger Desert sand obtained by the method of layering dry deposition showed obvious anisotropy. In the shear process, the test results of different $b$ values showed that the stress-strain relationships in the three orthogonal directions of the specimens were all of hardened type, and, with the changes of $b$-value, the stress-strain relationships in the three major directions have obvious differences. The peak of generalized shear stress increased with the increase of $b$-value. The specimens showed contractive behavior first and then dilatancy under the condition of $b=0$, while the others showed the characteristics of contractive behavior as a whole. The anisotropy of aeolian sand in Tengger Desert provided a reference for the longterm stability of sandy subgrade under traffic cycle load. 
The true-triaxial test results of dense specimens with different confining pressure showed that the stress-strain relationships in 3D were hardening at low confining pressure. The characteristic of contractive behavior was not obvious, which was mainly manifested as dilatancy. As the confining pressure increased, the characteristic of contractive behavior increased gradually, and the characteristic of dilatancy weakened. The specimen as a whole got from dilatancy to contractive behavior.

This study could provide reliable data for the design and stability analysis of subgrade construction in Tengger Desert. The above results have certain reference significance for the site selection of building subgrade in aeolian sand area, the strength design and settlement calculation in actual engineering, and the later maintenance of desert highway.

\section{Data Availability}

The data used to support the findings of this study are available from the corresponding author upon request.

\section{Conflicts of Interest}

The authors declare that there are no conflicts of interest regarding the publication of this paper.

\section{Acknowledgments}

This work was financially supported by the National Key R\&D Program of China (no. 2017YFC0504404), the Key R\&D Program of Ningxia Hui Autonomous Region Projects of International Cooperation and Exchanges (no. 2018DWHZ0084), and the National Natural Science Foundation of China (no. 51669027), and these supports are gratefully acknowledged.

\section{References}

[1] Y. Liu, X. H. Wang, X. Zhang, and B. P. Zhang, "Desertification process and its driving forces in the dune-activation region between the badain juran and Tengger Deserts," Arid Zone Research, vol. 28, no. 6, pp. 957-966, 2012.

[2] Y. Q. Yuan and X. C. Wang, "Experimental research on compaction characteristics of aeolian sand," Chinese Journal of Geotechnical Engineering, vol. 29, no. 3, pp. 360-365, 2007.

[3] Z. Y. Li, Y. W. Cao, N. X. Liang, and Y. J. Mei, "Compaction mechanism of aeolian sand," China Journal of Highway and Transport, vol. 19, no. 5, pp. 6-11, 2006.

[4] Y. Z. Yin and Y. L. Wang, "Study of key parameters in the process of aeolian sand compactibility," Applied Mechanics and Materials, vol. 580-583, pp. 278-282, 2014.

[5] Z. Z. Zeng and M. Y. Huang, "Study on the collapsibility of aeolian sand in the southern margin of Tengger Deserts," Journal of Gansu Sciences, vol. 12, no. 2, pp. 63-68, 2000.

[6] W. M. Shehata and A. A. Amin, "Geotechnical hazards associated with desert environment," Natural Hazards, vol. 16, no. 1, pp. 81-95, 1997.

[7] Q. Wang, Y. S. Liu, X. D. Fu, and W. X. Ren, "Reliability analysis for wetting deformation andstability of sand soil roadbed," China Journal of Highway and Transport, vol. 20, no. 6, pp. 7-12, 2007.
[8] Z. N. Li and J. N. Chang, "Structures of subgrade/pavement and construction techniques for the Taklimakan Desert Highway," Science in China Series D: Earth Sciences, vol. 45, no. 1, pp. 115-124, 2002.

[9] C. Li, Z. B. Dong, and X. J. Cui, "Grain size characteristics of transverse dune at different development stages in the southeastern margin of tengger deserts," Journal of Desert Research, vol. 35, no. 1, pp. 129-135, 2015.

[10] Y. H. Deng, X. A. Li, Z. J. Wang, Y. X. Song, and J. B. Peng, "Study on dynamic strength of the aeolian sand in $\mathrm{m}$ aow usu desert area," Engineering Mechanics, vol. 29, no. 12, pp. 281286, 2012.

[11] Y. X. Song, Test study on the mechanical property of the aeolian sand and the bearing capacity of the aeolian sand ground of $m u$ us desert, Ph.D. thesis, Changan University, Xi' an, China, 2011.

[12] D. P. Liu, X. H. Yang, J. Wang, and Z. J. Mao, "Study on static strength of aeolian sand before and after cyclic loading," Applied Mechanics and Materials, vol. 580-583, pp. 191-194, 2014.

[13] Kjellman, "Report on an apparatus for consummate investigation of the mechanical properties of soils," in Proceedings of the 1st International Conference on Soil Mechanics and Foundation Engineering, vol. 2, pp. 16-20, Cambridge, UK, June 1936.

[14] A. W. Bishop, "The strength of soils as engineering materials," Géotechnique, vol. 16, no. 2, pp. 91-130, 1966.

[15] H. Ko and R. F. Scott, "Deformation of sand at failure," Journal of Terramechanics, vol. 5, no. 4, pp. 67-74, 1968.

[16] H. B. Sutherland and M. S. Mesdary, "The influence of the intermediate principal stress on the strength of sand," in Proceedings of the 7th International Conference on Soil Mechanics and Foundation Engineering, vol. 1, pp. 391-399, Mexico City, Mexico, 1969.

[17] P. V. Lade and J. M. Duncan, "Cubical triaxial tests on cohesionless soil," Journal of Soil Mechanics \& Foundations Division, vol. 99, no. 10, pp. 793-812, 1973.

[18] G. X. Li, Discussion on three-dimensional constitutive relation of soil and model verification, Ph.D. thesis, Peking University, Beijng, China, 1985.

[19] M. Zhang, C. S. Xu, X. L. Du, G. S. Wang, and D. C. Lu, “A true triaxial test study on the effect of intermediate principal stress coefficients and stress paths on the shear characteristics of sand," Shuili Xuebao, vol. 46, no. 9, pp. 1072-1079, 2015.

[20] C. Tan, M.-d. Yuan, Y.-s. Shi, B.-s. Zhou, and H. Li, "Statistical damage constitutive model for cemented sand considering the residual strength and initial compaction phase," Advances in Civil Engineering, vol. 2018, Article ID 1410893, 9 pages, 2018.

[21] A. Schofield and P. Wroth, Critical State Soil Mechanics, McGraw-Hill, New York, NY, USA, 1968.

[22] Z. W. Xu and Z. Z. Ying, "True triaxial test of lateral deformation characteristics of silt," Chinese Journal of Geotechnical Engineering, vol. 19, no. 5, p. 626, 2000.

[23] P. Hu, M. S. Huang, S. C. Ma, and X. L. Lv, "True triaxial tests and strength characteristics of silty sand," Rock and Soil Mechanics, vol. 32, no. 2, pp. 465-470, 2011.

[24] J. Zhang, J. Cao, and S. Huang, "Effects of initial shear stress and vibration frequency on the dynamic pore-water pressure of saturated sands," Advances in Civil Engineering, vol. 2018, Article ID 6124809, 13 pages, 2018.

[25] B. Huang, Q. J. Wang, D. S. Ling, H. Ding, and Y. M. Chen, "Effects of back pressure on shear strength of saturated sand in triaxial tests," Chinese Journal of Geotechnical Engineering, vol. 34, no. 7, pp. 1313-1319, 2012. 
[26] Z. Li, H. B. Zhao, S. G. Liu, R. C. Xu, and Y. F. Wang, "Mechanical model for medium dense sand considering confining pressure effect and plastic evolution," Chinese Journal of Rock Mechanics and Engineering, vol. 37, no. 11, pp. 2610-2620, 2018.

[27] N. Shariatmadari, M. Karimpour-Fard, H. Hasanzadehshooiili, S. Hoseinzadeh, and Z. Karimzadeh, "Effects of drainage condition on the stress-strain behavior and pore pressure buildup of sand-PET mixtures," Construction and Building Materials, vol. 233, Article ID 117295, 2020.

[28] S. Krabbenhoft, J. Clausen, and L. Damkilde, "The bearing capacity of circular footings in sand: comparison between model tests and numerical simulations based on a nonlinear mohr failure envelope," Advances in Civil Engineering, vol. 2012, Article ID 947276, 10 pages, 2012.

[29] X. Q. Wang, J. Q. Lei, and Q. Huang, "Study on spatial distribution of wind-sand hazard along Tarim Desert highway," Journal of Desert Research, vol. 20, no. 4, pp. 438-442, 2000.

[30] Y. Yuan, X. Wang, and X. Zhou, "Experimental research on compaction characteristics of aeolian sand," Frontiers of Architecture and Civil Engineering in China, vol. 2, no. 4, pp. 359-365, 2008.

[31] M. El-Emam, "Experimental and numerical study of at-rest lateral earth pressure of overconsolidated sand," Advances in Civil Engineering, vol. 2011, Article ID 524568, 12 pages, 2011.

[32] P. X. Shu, B. S. Li, D. F. Niu et al., "Study on the characteristics of wind-sand in the southwest of the maowusu desert by using particle size data," Acta Geugraphica Sinica, vol. 36, no. 3, pp. $448-457,2016$.

[33] A. Skempton, "Effective stress in soils, concrete and rocks," Selected Papers on Soil Mechanics, vol. 1032, no. 3, pp. 4-16, 1984. 